\title{
Polyphenon Extraction Process From In vitro Culture of Camellia Sinensis L Callus With Ethyl Alcohol
}

\author{
Sutini ${ }^{1}$, Widiwurjani \\ Agrotechnology Department \\ Universitas Pembangunan Nasional "Veteran" Jawa Timur \\ Surabaya, Indonesia \\ ${ }^{1}$ sutini.agro@upnjatim.ac.id
}

\author{
Djoko Agus Purwanto \\ Department of Pharmaceutical Chemistry \\ Universitas Airlangga \\ Surabaya, Indonesia
}

\author{
Wirdhatul Muslihatin \\ Biology Department \\ Institut Teknologi Sepuluh Nopember Surabaya \\ Surabaya, Indonesia
}

\begin{abstract}
The purpose of this study was to obtain a polyphenon profile from callus extract obtained from in vitro culture of Camellia sinensis L. Polyphenon is one of the bioactive compounds found in Camellia sinensis $L$ plants which can also be produced through in vitro culture. Polyphenon as a bioactive is often used in various fields including in the fields of industry: manufacturing, food-drinks, health, agriculture, computers. To get a certain amount of polyphenon from in vitro culture, Camellia sinensis $\mathrm{L}$ callus was first extracted with water solvent, as well as non-water solvents / organic solvents such as ethyl alcohol. The methods used were: (1) inoculation of leaf explants from Camellia sinensis $L$ in vitro on the media plus growth regulators to form callus, (2) treatment to be able to be reused (3) reap the callus followed by callus weighing and callus observation. (3) extraction and isolation of bioactive polyphenon (4) identification of polyphenon from Camellia sinensis $L$ callus with high-performance liquid chromatography qualitatively and quantitatively. The results obtained are a form of polyphenon chromatogram profile from callus Camellia sinensis $L$ which resembles a standard chromatogram of polyphenon.
\end{abstract}

Keywords:cultured in vitro, callus Camellia sinensis L, polyphenon.

\section{INTRODUCTION}

The Camellia sinensis $L$ plant is uniquely unmatched with other plants, namely the integration between painting expression and tea drinking culture in China that has been passed down from generation to generation and has its own history which is a trademark culture [1]. Regarding the history and garden culture of tea gardens in Japan began consecutively in the Kamakura decade, tea gardens in the style of Buddhist temples and academy-style tea gardens [2]. Tea leaves have bioactive properties including polyphenon secondary metabolites which are often used in various fields including manufacturing industries for automobile and computer parts [3]. In the field of food and beverages can be functional food [4]. In the health environment it is useful for bactericidal, bacteriostatic and anti-oxidant $[5,6]$. Besides, it is useful for preventing and treating skin diseases. [7]. Polyphenon is widely found in various plants, for example in the leaves of Camellia sinensis L. This polyphenon is obtained from plants can also be produced through in vitro culture by optimizing the addition of growth regulators. [8] and a shikimic acid precursor [9] on a MS base medium [10] which is partially modified to form callus biomass. Polyphenon is one of the substrate chemical molecules obtained from the Camellia sinensis $L$ plant which has a number of phenol groups in its molecule with bioactive properties that contribute to anti-oxidants. Callus biomass that obtained through in vitro culture secondary metabolite content is influenced by the culture environment [11], extraction process and solvent used during extraction. The extraction process is bioactive material dissolved in organic solvent / ethanol [12], in glassware then excited with ultrasonic waves at a temperature of $35^{\circ} \mathrm{C}$, then the extraction results are activated using a rotary vacuum evaporator at $50^{\circ} \mathrm{C}[13]$

The purpose of this study was to obtain a polyphenon profile from callus extract that obtained from in vitro culture of Camellia sinensis L.

\section{MATERIAL AND METHODS}

Materials that used include leaf explants \& callus from Camellia sinensis L $40 \%$ ethyl alcohol [14,15] aquadest, in vitro culture materials, polyphenon standards and other materials purchased from Sigma nuclear.

The equipment that used are: (1) analytical balance (Shimadzu) with $0.001 \mathrm{mg}$ sensitivity, (2) filter "Nylon membrane filter" $0.2 \mu \mathrm{m}$, (3) pumpkin separating funnel, $5 \mathrm{ml}$ volumetric flask (4) rotavour, ultrasonic, ( 5) Highperformance liquid chromatography (HPLC) Shimadzu LC 20 AD with the specification: UV-ST diode array detector spectrophotometer, with the column RP 18 Waters $\mu$ Bondapak $10 \mu \mathrm{m}$. 
The experimental methods are: (1) inoculation of leaf explants from Camellia sinensis $L$ in vitro on the media plus growth regulators and optimization of the administration of shikimic acid to form callus precursors, (2) treatment to be able to be reused (3) reap the callus is followed by callus weighing and callus observation. (4) extraction and isolation of bioactive polyphenon (5) identification of polyphenon from Camellia sinensis $L$ callus with high-performance liquid chromatography qualitatively and quantitatively.

\section{A. Inoculation of leaf explants from Camellia sinensis L In vitro Culture}

Inoculation of explants from Camellia sinensis $L$ leaf tops in positions one to three was sterilized in a sterile solution (30\% baycline which was active at $5.25 \%$ (NaOCL) [16]. The explants planted in inoculation media were Murashige media and Skoog / MS enriched with kinetin growth regulators and 2,4-D with a concentration of $1 \mathrm{ppm}$.

\section{B. Treatment to be able to be reused}

Treatment that carried out is every ten days, carried out on new media with the same composition as inoculation media until callus is fifty-five days old [17]. After fifty-five days of age, weighing $100 \mathrm{mg}$ of callus was transferred to the treated medium which was treated by adding a precursor of shikimic acid 3 ppm.

Observed callus growth in treatment media with shikimic acid 3 ppm precursors in the range of time from zero days to forty days obtained callus biomass that is ready to be harvested.

\section{Reap the callus- weighing and observation}

Reap the callus and weigh the callus's wet weight to determine callus growth. Some other calluses were observed using a triocular microscope [18].

\section{Extraction and isolation of bioactive polyphenon}

Modification of the extraction process to obtain polyphenon biomass is $500 \mathrm{mg}$ of callus dissolved with $10 \mathrm{ml}$ of ethyl alcohol $40 \%$ [19], then macerated for 24 hours then being shaken for 2 hours at ultrasonic for 20 minutes [20], then filtered using filter paper Whatman No. 42. The solvent is evaporated using a rotary evaporator at $40-60{ }^{\circ} \mathrm{C}[21,22]$.

\section{E. Identification of polyphenon from Camellia sinensis $L$ callus}

Residues tha obtained from the evaporator are added with methanol until the volume becomes $5 \mathrm{ml}$ which is ready to be analyzed using HPLC [23]. Before being injected into HPLC a residue in methanol was carried out using an ultrasonic [24, 25] centrifuge and then filtered with an ultra filter to be ready to be injected into rheodine from HPLC to get the time and area retention of the chromatogram contained in HPLC for polyphenon identification

\section{RESULTS}

Inoculation of explants' result of Camellia sinensis $L$ in vitro culture with kinetin growth regulators and 2,4-D with a concentration of $1 \mathrm{ppm}$ were observed for changes in the physical form of explants to become the initial form of callus beginning can be observed as Table 1 .

\section{TABLE I. CHANGES IN THE PHYSICAL FORM OF EXPLANTS TO} CALLUS

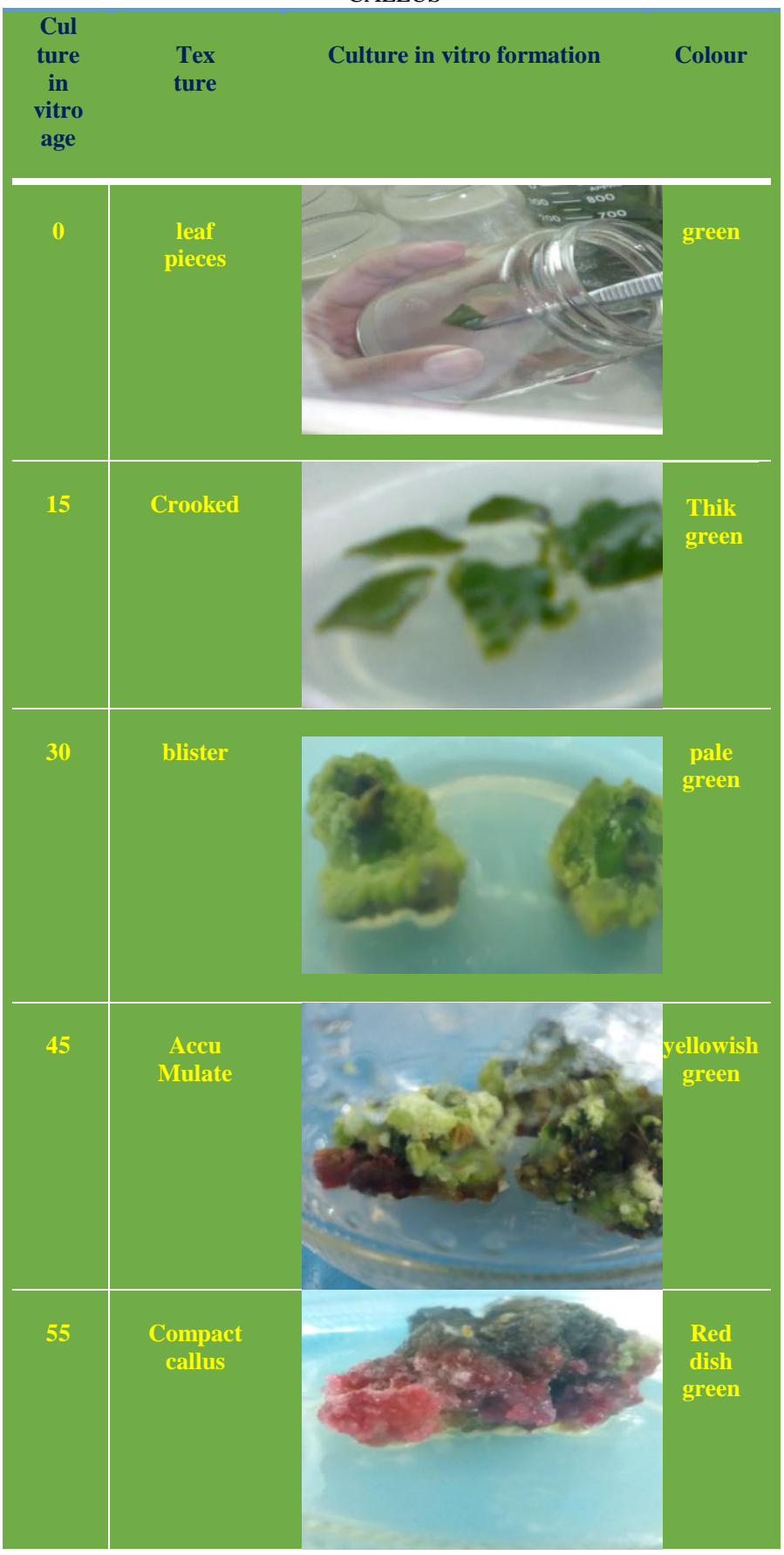

After the inoculation was obtained, the next callus biomass was treated with removal on the treatment medium by adding a precursor of shikimic acid $3 \mathrm{ppm}$. And then, the callus is 
chopped and weighed its wet weight in the span of zero days to forty days to see callus growth, can be seen in Figure 1.

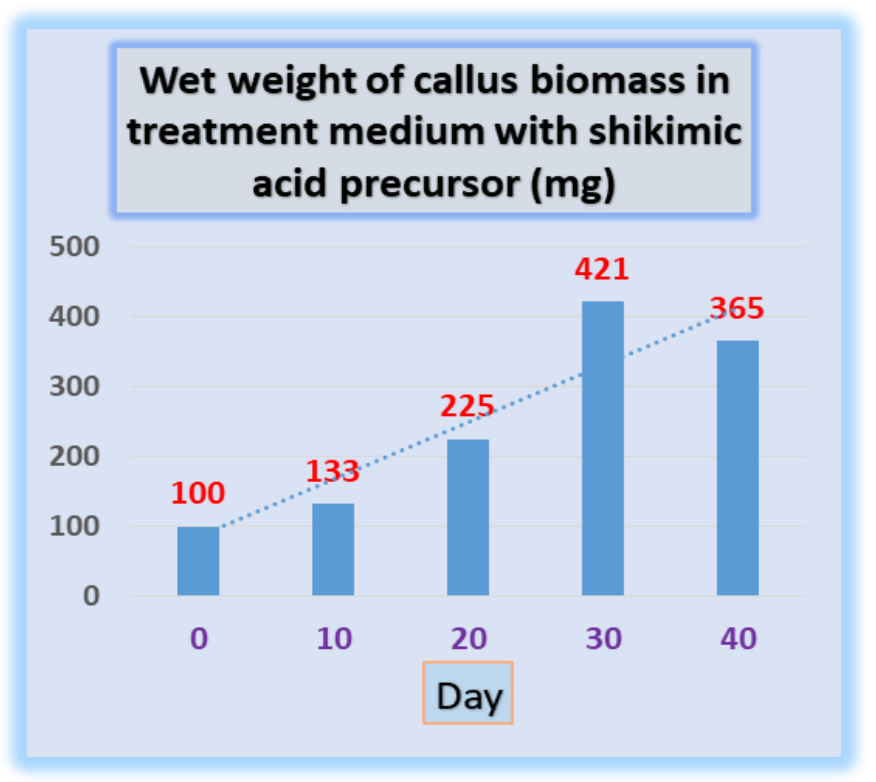

Fig. 1. Wet weight Callus biomass with an shikimic acid prekursor

Callus observations coupled with standard polyphenon cells using a triocular microscope are shown in Figure 2.
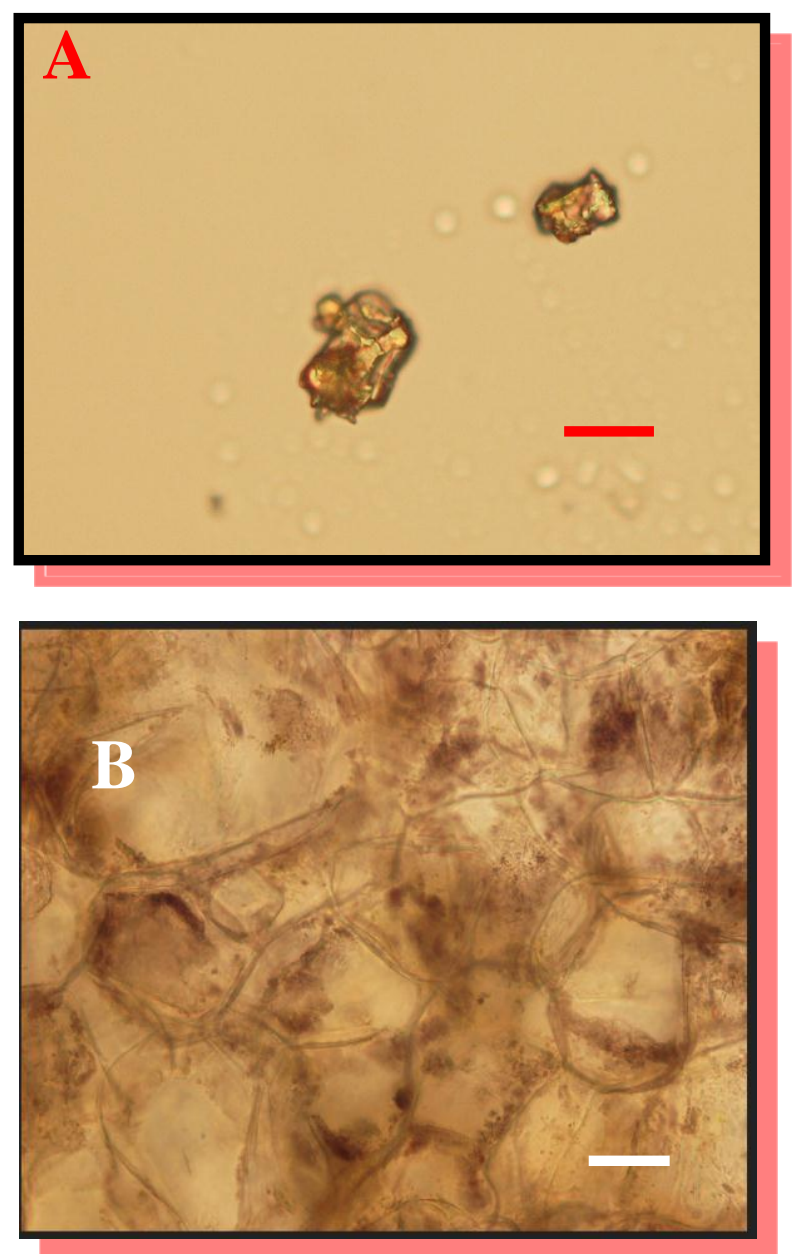

Fig. 2. Polyphenon standard cells (A), Polyphenon callus cells (B), $5 \mathrm{~mm}$ bars
Biomass from extraction and isolation using $40 \%$ ethyl alcohol which was combined with ultrasonic method for 20 minutes obtained thick biomass which is ready to be tested in High-performance liquid chromatography. The thick biomass of extraction and isolation results was dissolved in methanol and observed using High-performance liquid chromatography obtained by chromatogram, the data are listed in Figure 3
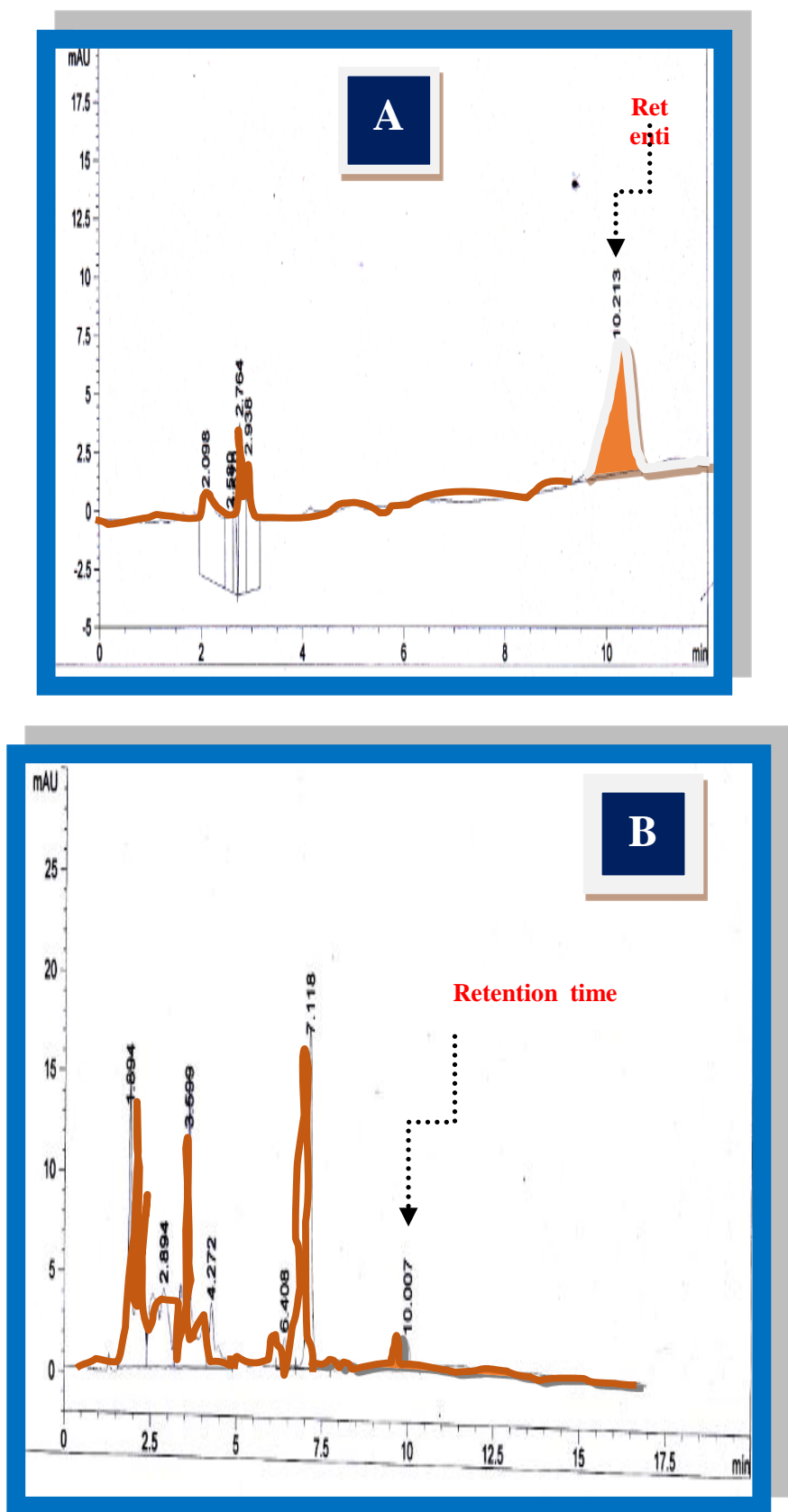

Fig. 3. Chromatogram of retention time and area polyphenon: A. (standard), B (sample)

\section{IV.DISCUSSION}

Identification of polyphenon from Camellia sinensis $L$ callus, in Table 1, changes in explants form callus at a range 
of 17 days after inoculation, which is a response to nutrient extraction from MS media by explant cuttings. Callus texture is generally compact with color variations ranging from greenish, pale green and reddish green.

Callus then grows which goes to the cell multiplication / prolifeization process. This cell proliferation is caused by the work of growth regulator substances kinetin and auxin. Growth regulating agent kinetin works in the regulation of protein synthesis which can accelerate cell division to result in callus growth. The substance that regulates the growth of auxin or 2,4-D [26], works to spread the cell wall so that the hydrogen bond is released. The release of hydrogen bonds will cause the entry of water into the cell, the pressure of the turgor will rise which will cause cell enlargement

In Figure 1, the treatment of callus growth reached a peak when in vitro culture was 30 days old, but after 40 days there was a decrease in this growth because shikimic acid changed its function to a herbicide compound which is responsible for the opposite of shikimic acid it self. Here is the importance of knowing when the time needed for optimum shikimic acid.

Shikimic acid can form a phenylpropanoid, framework (cinnamic acid) then the elongation of the units of cinnamic acid which will act with the malonic pathway to form a polyphenon skeleton compound [27]. The treatment of shikimic acid greatly affects callus growth because the acetic acid is a link between carbohydrate biosynthesis and polyphenon compounds [28]. Shikimic acid in vacuole is able to hydrolyze phosphate ester to produce Polyphenon bioactive $[29,30,31]$

Observation using a triocular microscope obtained callus cell form is almost the same as a standard cell. This shows that the clusal cells contain callus cells containing Polyphenon cells.

In Figure 3. the results of thick extracts from the organic solvent extraction process combined with ultrasonic $[32,33,34]$ then dissolved in methanol and injected on HPLC obtained standard Polyphenon retention time chromatogram which was the same as callus extract sample retention time. It can be said that the Camellia sinensis $L$ callus contains bioactve Polyphenon

\section{ACKNOWLEDGEMENT}

The author would like to acknowledge the Indonesian Directorate General of Research Technology and Higher Education, which has funded this research trough Competition Grants.

\section{REFERENCES}

[1] W. Li, "The Position and Role of Traditional Chinese Painting in the Tea Culture," Adv. Soc. Sci. Educ. Humanit. Res. (Assehr), vol. 103, pp.439-441

[2] A.Cheng, X. Chen, X.Liu, Y. Feng, M. Tan, and X.Yu, "The World in the Pot for Pottery Fun Analysis on Japanese Tea Garden," ICELAIC 2016, vol. 40, pp. 445-448.

[3] Y.Kharayat, Sh. V. K. Verma, B. Kumar, and C. S. Sharma, Phenols \& Phenolic Compounds Central Pollution Control Board (Ministry of Environment, Forests \& Climate Change) PariveshBhawan: East Arjun Naga, 2016, pp. 1-72

[4] K. Simanjuntak, A.Z. An'umillah, and L. Nurhayati, "Effect of Addition of Skim Milk in Tea To The Activity of Antioxidant Tea" Adv. Health Sci. Res. vol. 10 [1st International Integrative Conference on Health, Life and Social Sciences ICHLaS, 2017]

[5] N.Y. Gema and P.A. Ranu, "Effectiveness of Rinsing Black Tea Compared toGreen Tea in Decreasing Oral Bacterial Counts as anAlternative of Caries Prevention," Adv. Health Sci. Res., vol. 9, 2017 [2nd Public Health International Conference PHICo 2017, pp.19-2]

[6] H. Ishimoto, A. Tai, M. Yoshimura, Y. Amakura, T. Yoshida, T. Hatano and H. Ito, "Antioxidative Properties of Functional Polyphenols and Their Metabolites," J. Biosci. Biotechnol. Biochem., vol. 76, pp. 395399, 2012.

[7] D. Magdalena, J. Mierziak, U. Korzun, M. Preisner, A. Kulma and J. Szopa, "The Potential of Plant Phenolics in Prevention and Therapy of Skin Disorders,” Int. J. Mol. Sci., vol. 17, pp. 1-41, February 2016.

[8] S. Bidarig and E. Azarpour, " Study Effect Of Ba Hormone Levels On Length Shoot In-Vitro Culture Of Tea (Camellia sinensis L.)," Asian Res. Publ. Netw. (ARPN), vol. 8, pp. 86-89, January 2013

[9] G.N. Magoma, F.N. Wachira, M.O. Imbuga, and S.G. Agong, "Biochemical Differentiation in Camellia sinensis and Its Wild Relatives as Revealed by Isozyme," Biochem. Syst. Ecol., vol. 31, pp. 995-1010, 2003

[10] T. Murashige and F. Skoog, "A Revised Medium for Rapid Growth and Bioassays with Tobacco Tissue Cultures,” J. Physiol. Plant, vol. 15, pp. 473-497, 1962.

[11] R. Akula, G. Aswathanarayana, and Ravishankar, "Influence of Abiotic Stress Signals on Secondary Metabolites in Plants," J. Plant Signal. Behav., vol. 6, pp. 1720-1731, 2011.

[12] J.He and Q. Shen, "Optimization of Extraction key Process for Erinacine from Hericium erinaceus “, Int. Conf. Logist. Eng. Manag. Comput. Sci. (LEMCS 2015), pp. 211-220, January 2015

[13] M. Sholihah, U. Ahmad, and I.W. Budiastra, "Application of Ultrasonic Wave to Increase Extraction Yield and Effectiveness of Antioxidant from Mangosteen Rind," J. Keteknikan Pertan. (JTEP), vol. 5, pp. 161168, 2017.

[14] E. Suryanto, L.I. Momuat, M. Taroreh, and F. Wehantouw, "The Potency of Antioxidant Polyphenol from Goroho Banana (Musa sapien Sp.)," Agritech, vol. 31, pp. 289-296, 2011.

[15] E.B. Mojzer, M.K. Hrn`cǐc, M. Škerget, Ž. Knez, and U. Bren, "Polyphenols: Extraction Methods, Antioxidative Action, Bioavailability and Anticarcinogenic Effects," J. Mol., vol. 21, pp. 3-38, 2016.

[16] Y. Liu, Hb. Zhu, Jn. Lu, Lf. Li, Yz. Shi, and Xg.Yin, "High Concentration of Thidiazuron Stimulates Adventitious Bud Regeneration from Cotyledon Explants in Jatropha curcas," 4th Annual International Conference on Material Science and Engineering (ICMSE 2016), pp. 0085-0093.

[17] Sumaryono, I. Riyadi, J. S. Tahardi, "Morphological Variations During The Development of Somatic Embryos of Tea (Camellia sinensis L.) in vitro," Menara Perkeb., vol. 69, pp. 46-57, 2000

[18] T. Suzuki, N. Yamazaki, Y. Sada, I. Oguni, and Y. Moriyasu, "Tissue Distribution and Intracellular Localization of Catechins in Tea Leaves,", J. Biosci. Biotechnol. Biochem., vol. 6, pp. 2683-2686, 2003.

[19] S. Peng, Y. Yuan, J. Li, and X. Huang, "Study on ExtractionTechnology of Total Flavonoids from Alpinia officinarum Hance", Adv. Eng. Res. (AER), vol. 143[6th Int. Conf. Energy Arch. Pharm. Res., No 11, pp. 1114-1119, 2017 
[20] X. Qiu, J. Wang, M. Lu , and Y. Bi, "Study on The Factors Affecting Ultrasonic Extraction of Flavonoids from Grapefruit Seed," MCEI 2017 [7th Int. Conf. Mechatron. Comput. Educ. Inform., pp. 911-916]

[21] S.U. Handayani, M.S.K.T.S. Utomo, and M.E. Yulianto, "Performance Evaluation of Continuous Vibrating Fluidized Bed Dryer on Green Tea Production,” Adv. Sci. Lett., vol. 23, pp. 2530-2532, 2017.

[22] S. Zeng, Y. Li, D. Chen, Qi. Tang, Y. You, A. Liu, C. Feng, C. Li, and Y. Liu, "Optimum Extraction of Polysaccharides from Fruiting Body of Catathelasma ventricosum Using Response Surface Methodology", ICMEMTC 2016 [3rd Int. Conf. Mater. Eng. Manuf. Technol. Control, pp. 66-72].

[23] J. Gudej and M. Tomczyk,"Determination of Flavonoids, Tannins and Ellagic Acid in Leaves from Rubusb L. Species" Environ. Prot., vol. 27, pp. 1137-1142, 2004

[24] L. Haijun, G. Yuan, and L. Keyue, "Study on Extraction Process of flavonoids in Mollugo Pentaphylla by Microwave-ultrasonic Extraction with Semi-bionic Technology," EMIM 2015 [5th Int. Conf. Educ. Manag., Inf. Med., pp. 633-63]

[25] P. Champa, N. Whangchai, S. Jaturonglumlert, N. Nakao, and K. Whangchai, "Determination of Phytochemical Compound from Spirogyra Sp. Using Ultrasonic Assisted Extraction,” Int. J. Geomath., vol. 11, pp. 2391-2396, 2016.

[26] B.Rahayu, Solichatun, and E.Anggarwulan, "The effect of 2,4Dichlorophenoxyacetic Acid (2,4-D) on Callus Growth and Production Flavonoid Content on Culture Callus Acalypha indica L," Biofarm.,vol. 1, pp. 1-6,2003

[27] C.D. Broeckling, D.V. Huhman, M.A. Farag, J.T. Smith, P. Mendes, R.A. Dixon, L.W. Sumner, G.D. May, "Metabolic Profiling of Medicago Truncatula Cell Cultures Reveals The Effects of Biotic and Abiotic Elicitors on Metabolism,” J. Exp. Botan., vol. 56, pp. 323-336, 2004.

[28] I.A. Zelaya, J.A.H. Anderson, M.D.K. Owen, and R.D. Landes, "Evaluation of Spectrophotometric and HPLC Methods for
ShikimicAcid Determination in Plants: Models in Glyphosate-Resistant and Susceptible Crops ,"J. Agric. Food Chem., vol. 59, pp. 2202-2212, 2011.

[29] H. Hollji, N. Czytko, and N. Amrhein, "Subcellular Compartmentation of Shik imic Acid and Phenylalanine in Buckwheat Cel Suspension Cultures Grown in The Presence of Shikimate Pathway Inhibitors", Plant Sci. Lett., vol. 29, pp. 89-96,1983

[30] S. Xu, Md.M. Hossain, B.B.Y. Lau, T.Q. To, L. Aldous, and A. Rawal, "Total Quantification and Extraction of Shikimic Acid from Star Anise (Llicium Verum) Using Solid-State NMR and Cellulose-Dissolving Aqueous S Hydroxide Solutions," J. Sustain. Chem. Pharm., vol. xxxx, pp. $\mathrm{xxxx}-\mathrm{xxxx}, 2016$.

[31] H.S. Aldesuquy and A.H.A. Ibrahim, "The Role of Shikimic Acid in Regulation of Growth, Transpiration, Pigmentation, Photosynthetic Activity and Productivity of Vigna Sinensis Plants," J. Phyton [Horn, Austria], vol. 40, pp. 277-292, 2000.

[32] P. Alam, M.K. Parvez, A.H. Arbab, N.A. Siddiqui, M.S. Al-Dosary, A.J. Al-Rehaily, S. Ahmed, M.A. Kalam, and M.S. Ahmad, "Inter-species Comparative Antioxidant Assay and HPTLC Analysis of Sakuranetin in the Chloroform and Ethanol Extracts of Aerial Parts of Rhus retinorrhoea and Rhus tripartite," Pharm. Biology, vol. 55, pp. 1450 1457, 2017.

[33] M. Šeruga, I. Novak, and L. Jakobek, "Determination of Polyphenols Content and Antioxidant Activity of Some Red Wines by Differential Pulse Voltammetry, HPLC and Spectrophotometric Methods ", J. Food Chem., vol. 124, pp. 1208-1216, 2011.

[34] T. Seal, "Quantitative HPLC Analysis of Phenolic Acids, Flavonoids and Ascorbic Acid in Four Different Solvent Extracts of Two Wild Edible Leaves, Sonchus arvensis and Oenanthe linearis of North-Eastern region in India,” J. Appl. Pharm. Sci., vol. 6, pp. 157-166, 2016. 